https://helda.helsinki.fi

\title{
The implications of poaching for giant panda conservation
}

$\mathrm{Li}, \mathrm{Y}$.

Elsevier Science Ltd

2003

Li, Y. et al. 2003. The implications of poaching for giant panda conservation. Biological pÿConservation 111: 125136.

http://hdl.handle.net/1975/233

Downloaded from Helda, University of Helsinki institutional repository.

This is an electronic reprint of the original article.

This reprint may differ from the original in pagination and typographic detail.

Please cite the original version. 


\title{
The implications of poaching for giant panda conservation
}

\author{
Li Yiming ${ }^{\mathrm{a}, *}$, Guo Zhongwei ${ }^{\mathrm{a}}$, Yang Qisen ${ }^{\mathrm{a}}$, Wang Yushan ${ }^{\mathrm{a}}$, Jari Niemeläb \\ anstitute of Zoology, The Chinese Academy of Sciences, 19 Zhongguancun Lu, Haidian, Beijing 100080, China \\ ${ }^{\mathrm{b}}$ Department of Ecology and Systematics, PO Box 17, FIN-00014 University of Helsinki, Finland
}

Received 10 December 2001; received in revised form 8 August 2002; accepted 12 August 2002

\begin{abstract}
Poaching giant pandas (Ailuropoda melanoleuca) for their skins is a serious threat to the persistence of wild giant panda populations in China. An individual-based, age-structured stochastic simulation model was constructed to give a quantitative analysis of the effects of poaching. The model takes a total wild population of 1216 individuals divided among 16 'patches'. The model treats individual populations as being completely independent, with no dispersal, and density-dependence only enters into the model through local carrying capacity of patches. The model simulates three types of poaching: deterministic (constant) poaching, stochastic poaching with normal distribution and stochastic poaching with observed distribution. Results showed that, with a given initial population, poaching adult females produces lower average population size and higher average percentage extinction than poaching adult males or young. At the same poaching intensity, all three poaching simulations predicted a similar probability of extinction. However, they predicted different average population size and percentage extinction because of differences in the parameters in the three models. These results should therefore be treated with caution when constant poaching simulation or stochastic poaching with assumed normal distribution is used as a simplification of realistic poaching. Nevertheless, the results imply that giant pandas are threatened by any reduction in natural populations. Effective measures are essential to reduce poaching. It is also important to limit the capturing of wild animals for zoos or breeding facilities as this also has a serious effect on the total population.
\end{abstract}

(C) 2003 Elsevier Science Ltd. All rights reserved.

Keywords: Giant panda; Poaching; Simulation model; Viability

\section{Introduction}

The giant panda (Ailuropoda melanoleuca) is an endangered, endemic species in China and a 'flagship' species for conservation. Since the 1950s, it has been designated as top priority for species conservation in China. It lives in dense bamboo forests of mountainous areas and mainly eats bamboo shoots and leaves. It used to be widely distributed in southwest China, including Hunan, Hubei, Sichuan, Shaanxi and Gansu provinces in the 16-19th centuries (Zhu and Long, 1983) but today, it only occurs in Sichuan, Shaanxi and Gansu provinces. In the 1970s, its habitat was fragmented into six large patches in 45 counties (Fan and Song, 1996), while the second panda survey by the State

* Corresponding author. Tel.: +86-10-62574286; fax: +86-1062565689.

E-mail address: liym@panda.ioz.ac.cn (L. Yiming).
Forestry Administration found 16 patch populations during 1987-1988 (MOF and WWF, 1989) (Fig. 1).

The main threats to the giant panda include habitat destruction and fragmentation, logging (Zhu and Long, 1983; Hu et al., 1985; MOF and WWF, 1989), capturing for zoos (Hu, 1998a), poaching (Hu, 1998b; Li et al., 2000) and natural catastrophes such as the simultaneous flowering and dying of bamboo (Yang et al., 1981; Hu et al., 1985). Historically, the giant panda was killed for its skin and skull or captured for the imperial hunting park in China (Zhu and Long, 1983; Hu et al., 1985; MOF and WWF, 1989). Unfortunately, poaching remains a serious issue (Hu, 1998a; $\mathrm{Li}$ et al., 2000) but few studies have actually evaluated the effects of poaching on populations (Zhou and Pan, 1997).

A population viability analysis (PVA) is needed as a basis for conservation action. PVA simulation models can incorporate a range of threats that affect growth and persistence of small populations, including demographic and environmental stochasticity, catastrophes, 


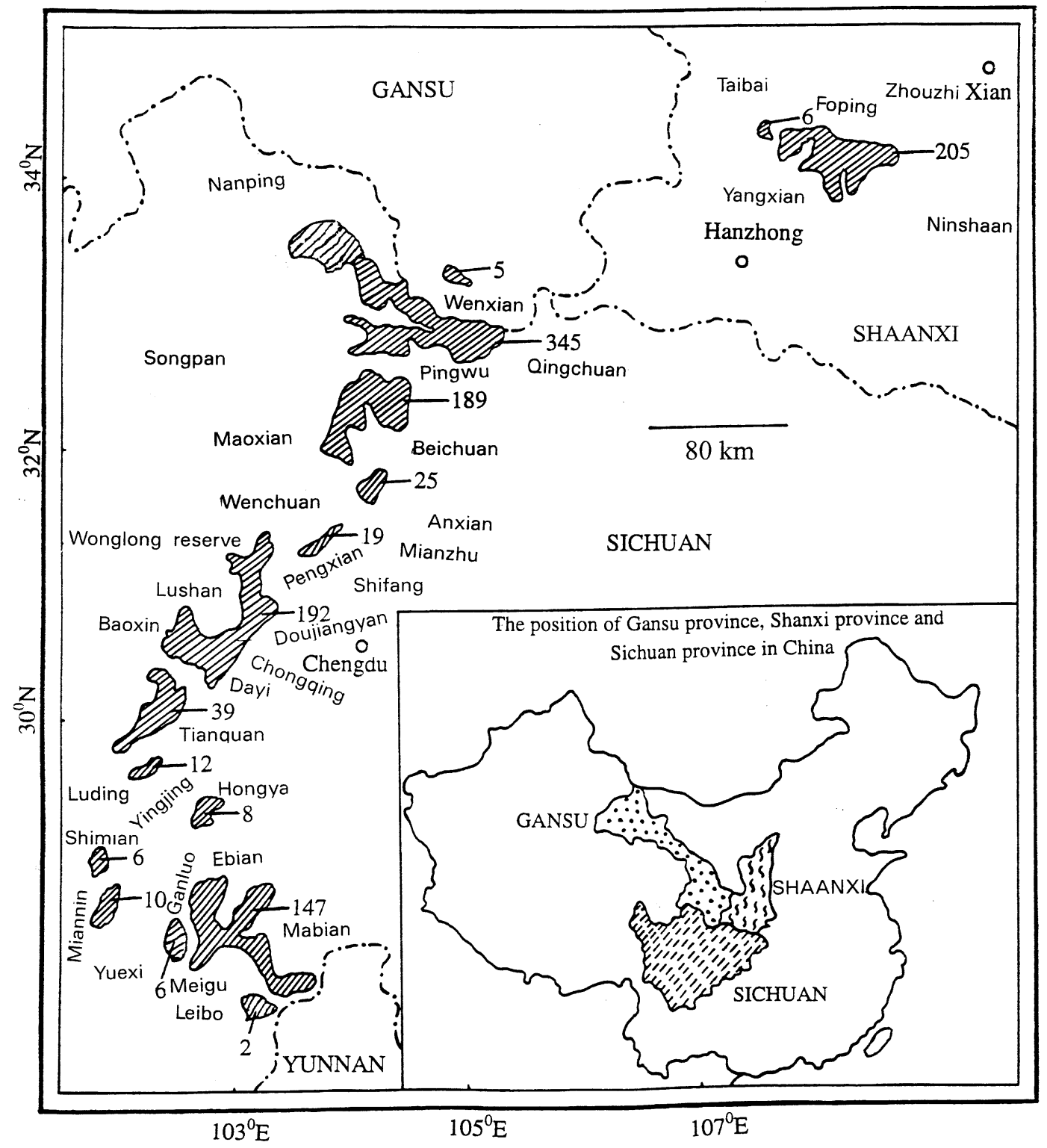

Fig. 1. The fragmented habitats and patch populations for the giant panda in 1989. The initial patch populations used in the model are given in each patch.

genetic stochasticity and system pressures such as habitat destruction (Gilpin and Soulé,1986; Burgman et al., 1993; Akcakaya et al., 1997). PVA is widely used to recommend management actions, assist reserve design, categorize species as endangered and assess the relative level of different threats faced by species (Gilpin and Soulé, 1986; Burgman and Lamont, 1992; Burgman et al., 1993; Possingham et al., 1993; IUCN, 1994; McCarthy and Lindmayer, 1999; Rushton et al., 2000a,b).

PVA requires detailed knowledge of species demography, ecology and life history to make realistic predictions (Boyce, 1992; Lacy, 1995; Brook et al., 2000; Chapman et al., 2001). However, for many endangered species, such data are usually difficult to collect owing to limitations of time and money, and data on poaching are especially difficult to collect since it is an illegal activity. However, it is such an important threat to many species (Pimm and Gilpin, 1989; McNeely et al., 1990), that there is increasing need to obtain such data and to assess its effects on population viability.

The aim of this paper is (1) to analyze the effects of poaching on population viability for the giant panda according to long-term data on confiscated skins from 1987 to 1998; (2) to assess the effects on wild populations of capturing giant pandas for zoos or breeding facilities; (3) to investigate differences between effects of deterministic poaching and stochastic poaching. The results are used to formulate conservation recommendations. 


\section{Methods}

\subsection{Model parameters}

For the population viability analysis, we used data collected during ca. 20 years (1974-1993) in the Wolong Reserve, Sichuan province. These included parameters on population demography (Wei et al., 1989; Wei and $\mathrm{Hu}, 1994 \mathrm{a}, \mathrm{b})$, sex ratio, age-specific mortality and carrying capacity.

\subsubsection{Initial patch population and total initial population}

We defined a 'patch population' of giant pandas as isolated by surrounding unoccupied, habitats, and the whole population as the sum of all patch populations. The 16 separate populations recorded during 1987-1988 are used as the initial patch populations in the model with a total initial population of 1216 individuals (Fig. 1). The distances between patch populations range from several kilometers to hundreds of kilometers. Some studies have suggested that the giant pandas may not be able to disperse between these patches because they are unable to cross the surrounding agricultural fields, deforested areas and other habitat types lacking suitable food (Fan and Song, 1998; MOF and WWF, 1989). There are no data on their dispersal.

\subsubsection{Reproduction}

All adult females and males can potentially breed (Wei and Hu, 1994a; Zhu and Pan, 1997). The maximum age of pandas is 21 years. Females become sexually mature, i.e. adult, at the age of 7 years, and males at the age of 8 years. The sex ratio is $1: 1$. According to records of six wild adult females in 1979-1991 in the Wolong Reserve, they breed 15 times, 14 times with one cub and once with two cubs (Wei and Hu, 1994b). However, most females only care for one cub during years when they have two. Mean birth rate per adult female is therefore taken to be 0.667 cubs (Table 1). The distribution of cubs is very skew (non-normal). We assumed that there was no density-dependence in reproduction and that variation in reproduction performance was not correlated with variation in survival. No data exist for these parameters.

\subsubsection{Mortality}

The data on age structure of mortality is difficult to collect because of their long life and rarity. We used data on age-specific mortality based on age identification of 69 skulls and field study in Wolong Reserve (Table 1). The higher mortality at the adult stage is mainly attributed to old age. Adult males usually have higher mortality than adult females. We modelled the mortality at the level of the individual for all age groups. The probability of death for each individual was determined by sampling deviates from a uniform distribution in the range $0-1$. Thus, for example, for an individual subjected to adult male mortality of $14.16 \%$, all deviates in the range $0-0.8584$ corresponded to the individual surviving, and those $>0.8584$ and up to 1.0 corresponded to it dying. All mortality rates were varied as model inputs. The mortality was assumed to occur after all breeding.

\subsubsection{Age distribution}

Two studies have suggested that age distribution of giant pandas is stable (MOF and WWF, 1989; Zhou and Pan, 1997). We therefore used a stable age structure for the start of our simulation (van Groenendael et al., 1988). Using the age-specific mortality and mean birth rate in Table 1, and the total initial population, we constructed a Leslie matrix model with density-independence (Leslie, 1945; Pielou, 1971). We ran the model and checked the relative percentage error of each age group between year $t$ and year $t+1$ in the population. A stable age distribution is obtained when the relative percentage error of each age group is $<2 \%$. The method for calculating the stable age distribution is not as precise as the analytic method (Leslie, 1945) but the results met the requirements of the study.

\subsubsection{Carrying capacity}

Wei and $\mathrm{Hu}$ (1994a) estimated that the panda population at Wolong consumed $50 \%$ of the eatable bamboo crop. We therefore assumed that the Reserve could support twice this population and we set the carrying capacity of a patch to be twice the initial patch population in our model.

\subsubsection{Catastrophes}

Two large catastrophes have occurred since 1920, one in the 1970s causing the death of 138 individuals (Wei and $\mathrm{Hu}, 1994 \mathrm{a}$ ), and another one in 1983-1987 causing the death of 141 individuals (Meng, 1989). Using the total initial population, we estimated the frequency and intensity of such catastrophes (Table 1).

\subsubsection{Poaching}

A total of 52 giant panda skins were confiscated between 1987 and 1998 (Li et al., 2000). The pandas poached include both sexes and all age groups. At least one panda was killed accidentally by a poacher who intended to trap other animals with snares. Fig. 3B (grey bar) shows the distribution of the poaching, which is non-normal. The maximum poaching intensity is 10 individuals a year and the minimum intensity is two individuals a year. A $\mathrm{Chi}^{2}$ test shows that there is no significant difference between the distribution of population sizes and distribution of number of skins poached among the three provinces (Li Y., unpublished data), indicating that the number of pandas poached is pro- 
Table 1

Parameters used in the model (see context)

(1) Age specific mortality

$\begin{array}{lc}\text { Age (male) } & \text { Mortality }(\%) \\ 1 & 40.00 \\ 2 & 9.67 \\ 3 & 3.14 \\ 4 & 1.52 \\ 5 & 1.55 \\ 6 & 1.57 \\ 7 & 1.60 \\ 8 & 3.45 \\ 9-21 & 14.16\end{array}$

$\begin{array}{lc}\text { Age (female) } & \text { Mortality }(\%) \\ 1 & 40.00 \\ 2 & 9.67 \\ 3 & 3.14 \\ 4 & 1.52 \\ 5 & 1.55 \\ 6 & 1.57 \\ 7 & 1.60 \\ 8-21 & 13.33\end{array}$

(2) Fecundity: all adults are breeding. A mean birth rate per adult female $=0.667$ (S.D. $=0.565, n=24$ ). Only $4.17 \%$ of adult female produce two cubs and $58.33 \%$ of adult female produce one cub annually;

(3) Sex ratio: 1:1;

(4) Carrying capacity: two times the initial patch populations (see Fig. 1);

(5) Catastrophe: frequency is once every 40 years and $11.47 \%($ S.D. $=0.174 \%, n=2)$ of the individual die as a consequence;

(6) Poaching: total 52 pandas killed during 1987-1998, average 4.33(S.D. $=2.46, n=12$ ) individuals each year (see Fig. 3B).

portional to population size among the provinces. We therefore assume a positive correlation between patch population size and pandas poached for all patch populations and all age groups in the simulation.

\subsubsection{Capturing wild giant pandas for zoos and breeding facilities}

It is estimated that about 240 individuals in the wild have been captured for zoos or breeding facilities during the 40 years from the mid 1950s to mid 1990s ( Hu, 1998a), an average of six individuals per year. About 110 pandas were captured from Baoxin county and 60 from Pingwu county because large patch populations were distributed in these two counties. There are no data available on distribution of capturing so we assumed that this was similar to that for poaching in our simulations.

\subsection{Structure of the simulation model}

An individual-based, age-structured, stochastic simulation model was constructed specifically for giant panda populations (Fig. 2). The model can simulate and trace the fate of each patch population and each individual. The model treats each patch as an isolated population with its own ceiling on carrying capacity. It treats new-born cubs as in their first year and individuals older than 21 years would die. The model assumes that agespecific mortality, catastrophe frequency and resulting mortality, the distribution of number of cubs and the sex ratio all follow a binormial distribution. The survival and fecundity of each individual panda is determined on an annual basis by choosing a random number from a uniform distribution $(0,1)$. If the random number is larger than the mortality, then the indi- vidual giant panda survives to the next year. The model assumes that adult females in a patch population can only breed when there is at least one adult male in the patch. The number of cubs per year produced by an adult female is chosen from a distribution of cubs.

Three types of poaching behaviour were simulated by the model:

1. Deterministic (constant) poaching (CP). The number of individuals poached per year in a population is constant.

2. Stochastic poaching with a normal distribution (SPND) of constant expected value. The number of individuals poached per year in a population is randomly determined from a normal distribution with constant expected value.

3. Stochastic poaching with observed distribution (SPOD). The number of individuals poached per year in a population is randomly selected from the observed poaching distribution.

In all three types of poaching behaviour, the model assumes that the number of pandas poached each year in a patch population or an age group is proportional to the size of the patch population or the age group.

The model considers a patch population extinct when the last individual in the patch is dead, and the whole population extinct when all patch populations have gone extinct. Each simulation begins with the initial population with stable age structure. Model output is extinction probability, average population size and average percentage extinction of initial patch populations (abbreviated average percentage extinction) in each 10 -year interval. 


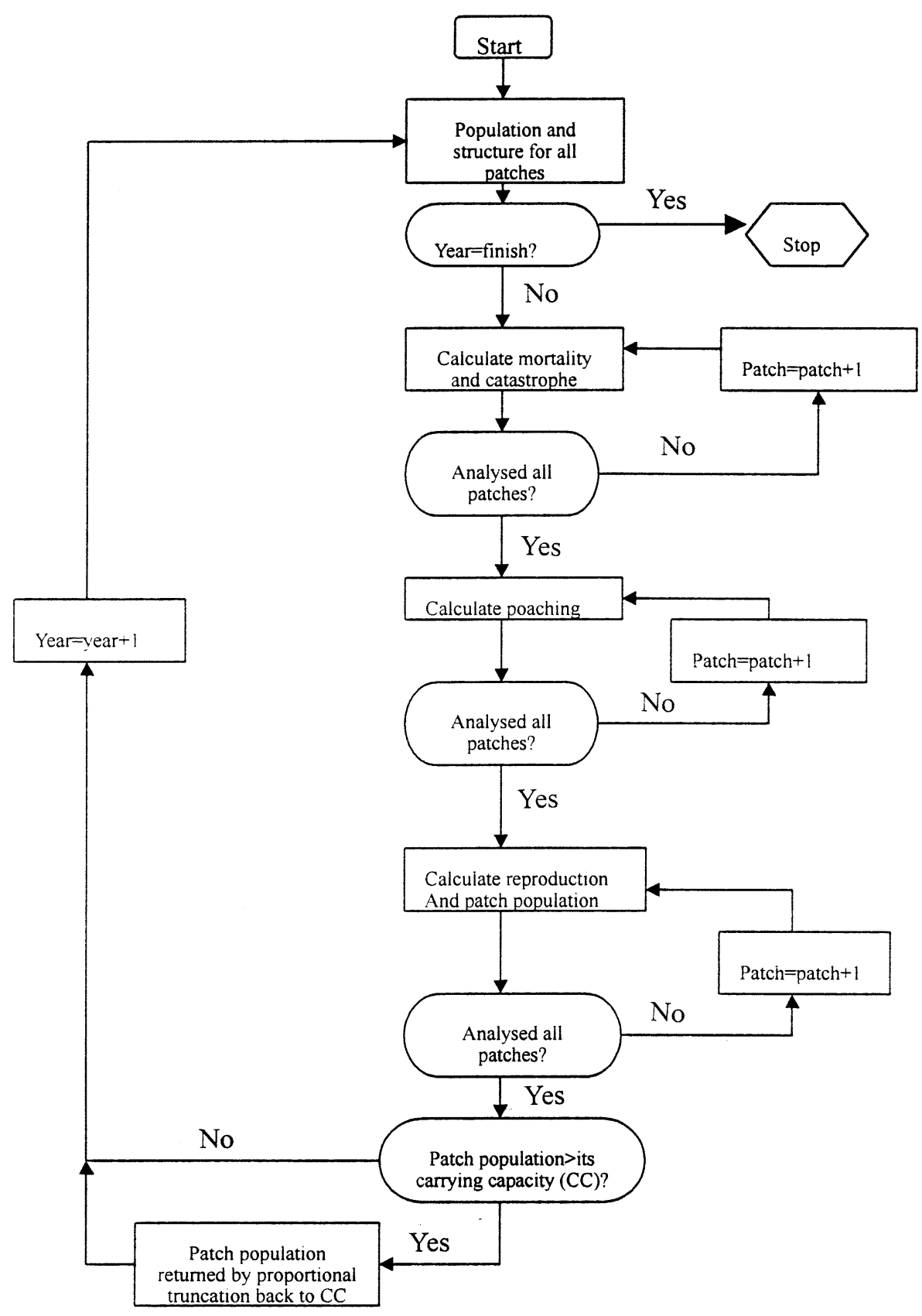

Fig. 2. Flow chart showing the structure of the population dynamics for the giant panda.

\subsection{Poaching and capturing simulation scenarios}

Two poaching intensities (four individuals and eight individuals each year) were simulated for the constant poaching. Four poaching intensities ( $4 \pm 1.687$ individuals, $4.33 \pm 1.738$ individuals, $8 \pm 2.493$ individuals and $8.66 \pm 2.56$ individuals each year ) were simulated for stochastic poaching with assumed normal distribution. Two poaching intensities $(4.33 \pm 2.460$ individuals and $8.66 \pm 4.917$ individuals each year) were modelled for stochastic poaching with observed distribution. For the two stochastic models, the distribution of each poaching intensity was obtained from 50,000 simulations (Fig. 3AD). With observed distribution, the poaching at 4.33 individuals per year and at 8.66 has the same distribution but parameters of poaching at 8.66 are twice as great as corresponding values at 4.33 (see Table 1 and Fig. 3). A capturing intensity of six individuals a year was chosen for the constant capturing simulation and stochastic simulation with assumed normal distribution $(6 \pm 2.321)$. 

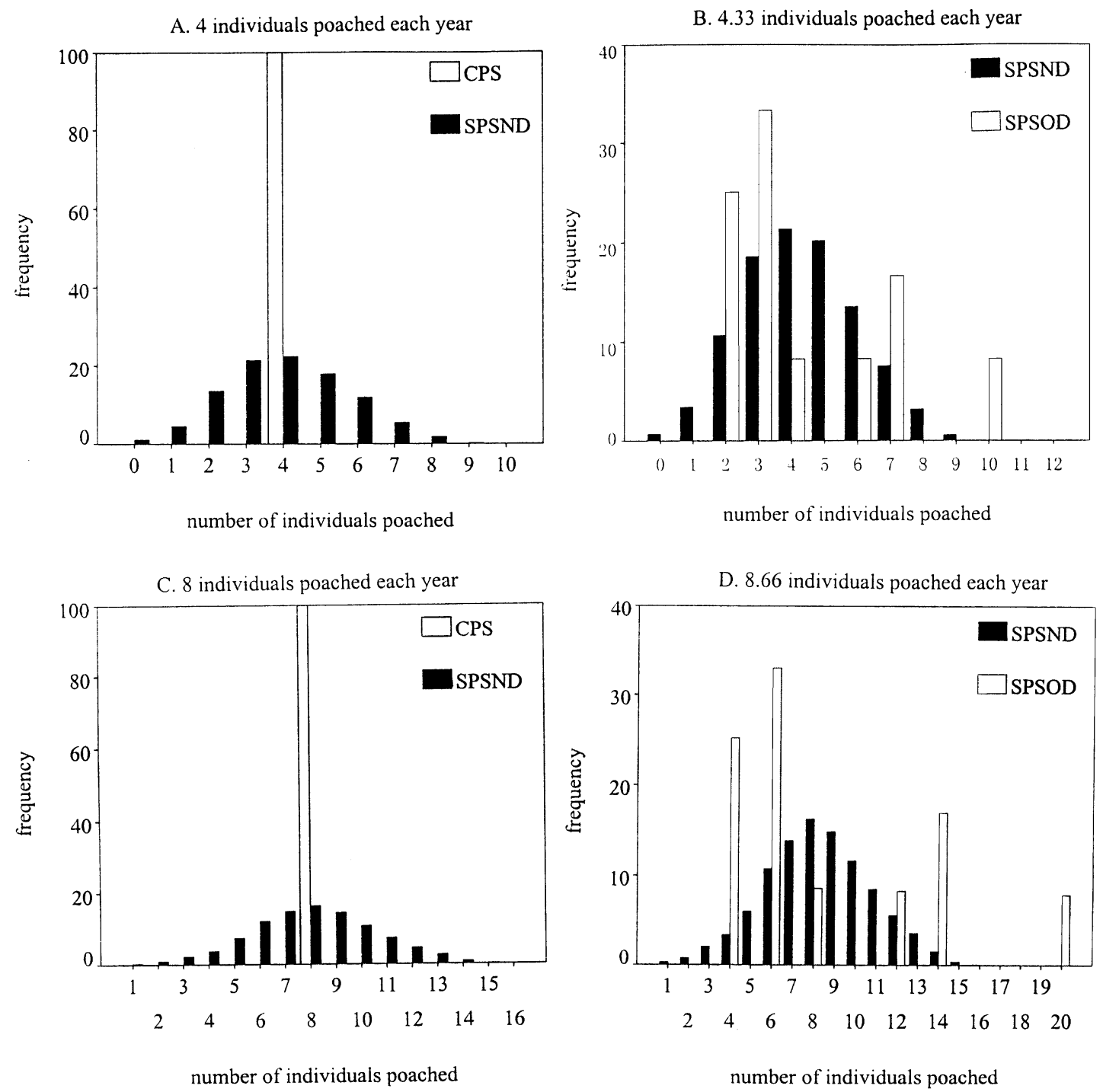

Fig. 3. Comparisons of parameters of poaching among three poaching simulations. Grey bar in B shows distribution of poaching for the giant panda during 1987-1998.

\subsection{Sensitivity analysis}

The sensitivity of the model to its input parameters was investigated by running the model under a range of input parameters. Stratified random sampling (Krebs, 1999) was used to select population parameters from a range (lower and upper limit) of input values for each variable that could potentially occur in the field. The probability distribution for each variable is divided into $n$ intervals of equal probability, where $n$ is the number of sets/suites of input variables selected. A random number is used to select an interval and another random number to determine the position and hence the value of the input variable for inclusion in the set (Rushton et al., 2000a,b). The model could be run a sufficiently large number of times to encompass the complete range of conditions that occurred naturally. The sample values of input parameters were selected by using a randomization procedure from a universe of possible values. A total of seven parameters were considered (Table 2). There were no data available on range of input values for five parameters. Zhou and Pan (1997) documented that about $44.44 \%$ of female adults produced one cub each year, about $80 \%$ of that estimated by Wei and $\mathrm{Hu}$ (1994a). Zhou and Pan (1997) estimated that mortality of adult females is $14.29 \%$, about $107 \%$ of the estimate from Wei and Hu's study. We therefore selected values from the range $0.8-1.2$ of present values (Table 1) for these parameters in the sensitivity analysis (Table 2). This range may cover a wider range of variation of these parameters. The analysis begins with the initial population. The population output was used as a response variable to correlate with input parameters and partial correlation coefficients were calculated to investigate 
Table 2

The parameter ranges used in the sensitivity analysis of the giant panda population

\begin{tabular}{llll}
\hline & Minimum & Maximum & Reference \\
\hline Male mortality & $0.8^{\mathrm{a}}$ & $1.2^{\mathrm{a}}$ & No published data \\
Female mortality & $0.8^{\mathrm{a}}$ & $1.2^{\mathrm{a}}$ & No published data \\
Catastrophe frequency (\% per year) & 1.667 & 2.500 & Wei and Hu (1994a) \\
Catastrophe mortality & $0.8^{\mathrm{a}}$ & $1.2^{\mathrm{a}}$ & No published data \\
Percentage of adult females producing one cub & $0.8^{\mathrm{a}}$ & $1.2^{\mathrm{a}}$ & No published data \\
Carrying capacity & $1.0^{\mathrm{b}}$ & $2.00^{\mathrm{b}}$ & Wei and Hu (1994a); Zhu and Pan (1997) \\
Poaching (No. of ind. per year) & 0 & 10 & Li et al. (2000) \\
\hline
\end{tabular}

a Multiplying present values (see Table 1).

b Multiplying initial patch population (see Fig. 1).

effects of each input variable on the population by multivariate stepwise linear regression (SAS, 1993). The analysis was run for 200 sets of data for 100 years (Rushton et al., 2000a,b).

\subsection{Data analysis}

The comparisons of different simulation scenarios were based on probability of extinction, average population sizes over persisting replicates and average percentage extinction predicted by the model. By excluding those replicates going extinct, the average population size is independent of the reported probabilities of extinction. Differences between different simulation screens were analyzed using a $t$-test for average population size and average percentage extinction, and contingency $\mathrm{Chi}^{2}$ test for extinction probability (Chapman et al., 2001). For all comparisons the significant level is 0.05 .

\section{Results}

\subsection{Sensitivity analysis}

An analysis of multivariate stepwise linear regression relating variations in model input parameter is shown in Table 3. The most important variables determining predicted population size is female mortality and percentage of adult females producing one cub. Female mortality is negatively correlated with population size, but the percentage of adult females producing one cub is positively related to population size. Carrying capacity, poaching, catastrophe mortality and male mortality are also important. Catastrophe frequency is not important because these events are so rare.

\subsection{Effects of poaching on population dynamics}

Even without poaching, the population growth of the giant panda is very low. The average geometric growth rate is 1.0032 (S.D. $=0.00145$ ) and the population reaches $1642( \pm 210)$ individuals in 100 years (Table 4). However, an average of $3.517 \%$ (S.D. $=1.425)$ of the initial patch populations become extinct. Under all poaching scenarios, the total population does not go extinct (Table 4), but the population declines and the average percentage extinction increases, compared to populations without poaching. As poaching intensity increases, the population decreases and the average percentage extinction increases (Table 4).

Selective poaching affects the population dynamics in different ways. Poaching of females causes a sig-

Table 3

The partial correlation coefficient squares $\left(R^{2}\right)$ and $t$ value relating the predicted population to the parameters used in the model by the multivariate stepwise linear regression

\begin{tabular}{lrrr}
\hline Parameters & Partial $R^{2}$ & $t$ Value & Probability \\
\hline Male mortality & -0.145 & 2.040 & 0.043 \\
Female mortality & -0.965 & 53.327 & $<0.001$ \\
Percentage of adult female producing one cub & 0.914 & 31.263 & $<0.001$ \\
Catastrophe frequency & -0.045 & 0.622 & 0.535 \\
Catastrophe mortality & -0.331 & 4.877 & $<0.001$ \\
Carrying capacity & 0.846 & 22.016 & $<0.001$ \\
Poaching intensity & -0.452 & 7.037 & $<0.001$ \\
\hline
\end{tabular}


Table 4

Average population size $n$ (with standard deviation) and average percentage extinction of initial patch populations (PE) under three poaching scenarios in 100 years $^{\mathrm{a}}$

\begin{tabular}{|c|c|c|c|c|c|c|}
\hline \multicolumn{2}{|c|}{ Poaching intensity (ind./year) } & \multirow{2}{*}{$\begin{array}{l}0 \\
1642(210)\end{array}$} & \multirow{2}{*}{$\begin{array}{l}4 \\
1223(222)\end{array}$} & \multirow{2}{*}{$\begin{array}{l}4.33 \\
-\end{array}$} & \multirow{2}{*}{$\frac{8}{721(200)}$} & \multirow{2}{*}{$\begin{array}{l}8.66 \\
-\end{array}$} \\
\hline $\mathrm{CP}$ & $n$ (S.D.) & & & & & \\
\hline & PE\% (S.D.) & $3.52(1.43)$ & $4.09(1.62)$ & - & $4.92(1.83)$ & \\
\hline \multirow[t]{2}{*}{ SPND } & $n$ (S.D.) & $1642(210)$ & $1220(225)$ & $1195(220)$ & $744(204)$ & $670(206)$ \\
\hline & PE\% (S.D.) & $3.52(1.43)$ & $3.91(1.54)$ & $4.01(1.61)$ & $4.89(1.88)$ & $5.31(2.09)$ \\
\hline \multirow[t]{2}{*}{ SPOD } & $n$ (S.D.) & $1642(210)$ & - & $1176(222)$ & - & $653(215)$ \\
\hline & PE\% (S.D.) & $3.52(1.43)$ & - & $4.22(1.63)$ & - & $5.11(2.29)$ \\
\hline
\end{tabular}

a Extinction probability of total initial population is zero in all cases. CP: constant poaching; SPND: stochastic poaching simulation with normal distribution; SPOD: stochastic poaching simulation with observed distribution. Total initial population is 1216 individuals.

Table 5

Effects of selective poaching on the giant panda ${ }^{\mathrm{a}}$

\begin{tabular}{|c|c|c|c|c|c|}
\hline Poaching intensity (ind./year) & & 4 & 4.33 & 8 & 8.66 \\
\hline \multicolumn{6}{|l|}{ Poaching young } \\
\hline \multirow[t]{3}{*}{$\mathrm{CP}$} & $n$ (S.D.) & $1221(220)$ & - & 757 & - \\
\hline & PE\% (S.D.) & $4.01(1.56)$ & - & $4.85(1.88)$ & - \\
\hline & Ex. Prob. & 0.00 & - & 0.00 & - \\
\hline \multirow[t]{3}{*}{ SPND } & $n$ (S.D.) & $1225(217)$ & $1211(219)$ & $763(208)$ & $681(221)$ \\
\hline & PE\% (S.D.) & $4.03(1.61)$ & $3.97(1.59)$ & $4.83(1.88)$ & $4.76(1.83)$ \\
\hline & Ex. Prob & 0.00 & 0.00 & 0.00 & 0.00 \\
\hline \multirow[t]{3}{*}{ SPOD } & $n$ (S.D.) & - & $1198(217)$ & - & $657(218)$ \\
\hline & PE\% (S.D.) & $-4.14(1.67)$ & - & $5.15(2.09)$ & \\
\hline & Ex. Prob & - & 0.00 & - & 0.00 \\
\hline \multicolumn{6}{|l|}{ Poaching adults } \\
\hline \multirow[t]{3}{*}{$\mathrm{CP}$} & $n$ (S.D.) & $1021(232)$ & - & 459 (196) & - \\
\hline & PE\% (S.D.) & $4.24(1.64)$ & - & $5.81(3.54)$ & - \\
\hline & Ex. Prob. & 0.00 & - & 0.00 & - \\
\hline \multirow[t]{3}{*}{ SPND } & $n$ (S.D.) & $1015(221)$ & $978(231)$ & 503 (194) & 394 (186) \\
\hline & PE\% (S.D.) & $4.19(1.90)$ & $4.19(1.72)$ & $5.44(3.32)$ & $6.56(5.70)$ \\
\hline & Ex. Prob & 0.00 & 0.00 & 0.00 & 0.02 \\
\hline \multirow[t]{3}{*}{ SPOD } & $n$ (S.D.) & - & 985 (217) & - & 377 (182) \\
\hline & PE\% (S.D.) & $-4.33(1.62)$ & - & $6.66(6.69)$ & \\
\hline & Ex. Prob & - & 0.00 & - & 0.02 \\
\hline \multicolumn{6}{|l|}{ Poaching males } \\
\hline \multirow[t]{3}{*}{$\mathrm{CP}$} & $n$ (S.D.) & 1613 (199) & - & $1608(217)$ & - \\
\hline & PE\% (S.D.) & $3.61(1.40)$ & - & $3.58(1.41)$ & - \\
\hline & Ex. Prob. & 0.00 & - & 0.00 & - \\
\hline \multirow[t]{3}{*}{ SPND } & $n$ (S.D.) & 1629 (199) & $1630(205)$ & $1619(205)$ & $1609(212)$ \\
\hline & PE\% (S.D.) & $3.49(1.42)$ & $3.47(1.48)$ & $3.49(1.54)$ & $3.38(1.39)$ \\
\hline & Ex. Prob & 0.00 & 0.00 & 0.00 & 0.00 \\
\hline \multirow[t]{3}{*}{ SPOD } & $n$ (S.D.) & - & $1622(200)$ & - & $1587(207)$ \\
\hline & PE\% (S.D.) & $-3.46(1.38)$ & - & $3.56(1.41)$ & \\
\hline & Ex. Prob & - & 0.00 & - & 0.00 \\
\hline \multicolumn{6}{|l|}{ Poaching females } \\
\hline \multirow[t]{3}{*}{$\mathrm{CP}$} & $n$ (S.D.) & $746(215)$ & - & $24(43)$ & - \\
\hline & PE\% (S.D.) & $5.12(2.01)$ & - & $64.28(36.77)$ & - \\
\hline & Ex. Prob. & 0.00 & - & 0.432 & - \\
\hline \multirow[t]{3}{*}{ SPND } & $n$ (S.D.) & $745(210)$ & $676(210)$ & $27(51)$ & $12(19)$ \\
\hline & PE\% (S.D.) & $5.04(2.03)$ & $5.06(1.86)$ & $63.85(36.93)$ & 84.09 (28.68) \\
\hline & Ex. Prob & 0.00 & 0.00 & 0.406 & 0.708 \\
\hline \multirow[t]{3}{*}{ SPOD } & $n$ (S.D.) & - & $658(210)$ & - & $20(41)$ \\
\hline & PE\% (S.D.) & $-5.36(2.12)$ & - & $83.79(30.12)$ & \\
\hline & Ex. Prob & - & 0.00 & - & 0.712 \\
\hline
\end{tabular}

a $n$ : Average population size; PE: average percentage extinction of initial patch populations; CP: constant poaching simulation; SPND: stochastic poaching simulation with normal distribution; SPOD: stochastic poaching simulation with observed distribution. Total initial population is 1216 individuals. Adults include adult males and adult females. 
nificantly lower population size and higher risk of extinction than poaching of males at the same intensity (Table 5). At a high female poaching intensity of 8 or 8.66 individuals a year, all populations have a very high extinction probability, and most of the initial patch populations become extinct. Likewise, poaching adults has a greater impact on patch populations than poaching young pandas, leading to lower population size and higher percentage extinction (Table 5).

\subsection{Effects of capturing panda for zoos or breeding facilities on the wild population}

The models show that capturing pandas for zoos or breeding facilities reduces the wild population. Without any capturing and poaching, the population could reach $1363( \pm 118)$ individuals and the average percentage extinction is $1.13 \%( \pm 0.66)$ in 40 years. At six individuals captured per year (without poaching), the constant capturing simulation and stochastic capturing simulation with normal distribution show lower average population size $(1150 \pm 110$ and $1126 \pm 113$ individuals, respectively) and higher average percentage extinction $(1.32 \pm 0.72 \%$ and $1.33 \pm 0.73 \%$, respectively) in 40 years.

\subsection{Comparisons of three poaching simulations}

All simulations - constant poaching (CP), stochastic poaching with normal distribution (SPND), and stochastic poaching with observed distribution (SPOD)give a similar prediction of extinction probability at the same poaching intensity in 100 years (Table 5). In most simulation scenarios, they may give similar predictions of average population size and percentage extinction at the same intensity. In some cases the three poaching simulations give different predictions of average population size and average percentage extinction at the same poaching intensity (Table 5). For example, the average population size differs significantly between stochastic poaching of females at 8.66 individuals per year with normal distribution and with observed distribution, and similarly for poaching at 4.33 individuals each year.

The difference in distribution of parameters of poaching simulation is mainly responsible for the different predictions among the three poaching simulations at the same intensity (Fig. 3). There is only $22.4 \%$ overlap of parameters at four individuals per year and $16.4 \%$ at eight individuals per year between constant poaching and stochastic poaching with normal distribution (Fig. 3A,C). For the latter, the ranges are 0-10 and 0-16 individuals for four and eight individuals per year respectively. On the other hand, the overlap between stochastic poaching with normal and with observed distributions is large (Fig 3B,D): about $53.4 \%$ at 4.33 individuals each year and $30 \%$ at 8.66 individuals each year. The range of parameters of poaching with observed distribution only has six values at each poaching intensity, while with normal distribution it ranges from $0-12$ individuals at 4.33 individuals per year and $0-19$ individuals at 8.66 individuals per year.

\section{Discussion}

\subsection{The model}

The ceiling model of population dynamics has been widely used to study viability of small populations (Stacey and Taper, 1992; Lande, 1993; Lacy, 1993; Middleton and Nisbet, 1997). These models are a reasonable simplification of density-dependent population growth. However, they have the disadvantage that when the population size $(N)$ reaches or exceeds the carrying capacity $(K), N$ resets to $K$ with a proportional truncation. This could lead to a change in population growth rate because the $N$ might oscillate in ways that have no relationship to reality. Brook et al. (2000) examined the validity of five models by using long-term data of 21 wildlife populations, which included eight species of birds, 11 mammals, one reptile and one fish species. They found these models including ceiling models are reliable. However, the ceiling model may be unrealistic when models predict the population viability of a cycling population (Chapman et al., 2001). The ceiling model can be used to assess the viability of giant panda (Wei and Hu, 1994a) because the populations do not fluctuate dramatically and the density-dependent relationship is not clear.

\subsection{Poaching simulation}

Poaching is a stochastic process related to human activities because it is very complicated and unpredictable. Both the number of illegal poachers and traders and the number of prey poached vary over time. In the field, the poacher does not know when, where or how many prey will be encountered, or to predict their age or sex or if he will be successful. Poaching is also affected by other factors, such as the black market, traditional cultures, religion, conservation legislation and conservation consciousness (Eltringham, 1984; McNeely et al., 1990; Mclean et al., 1999), and these factors can interact with each other.

Some studies have assessed poaching effects on population viability with the assumption that poaching is a deterministic process (poaching is constant) (Lu, 1992; Kenney et al., 1995; Zhou and Pan, 1997), but this represents a simplification of reality. However, little is 
known about the differences between the effects of deterministic poaching and those of observed poaching on population viability. Our results showed that the variance and distribution of poaching could influence the population dynamics of giant panda. All three types of poaching simulation predicted similar extinction probability, and, in most scenarios, similar average population size and percentage extinction. However, they may predict different average population size and extinction because of differences in distribution of poaching at the same intensity. It is therefore important to consider the distribution and variance of poaching when studying poaching effects. Long-term data on poaching are often difficult to collect so the predicted results should be treated with caution when constant poaching or stochastic poaching with normal distribution are used as a simplification of realistic poaching.

\subsection{Effects of poaching on giant pandas}

The severity of the poaching effect depends on the sex and age of the poached animals. Poaching females not only reduces the population size of the present generation, but also reduces the number of adult females and thus the number of new-born individuals in the following generation. Poaching males reduces the population size of the present generation, but does not influence the breeding success in the model, except when the poaching intensity is very high and the last male is killed in a patch population. Selected poaching can also change the age distribution.

Zhou and Pan (1997) assessed the viability of a population with 27 individuals in Qingling by a Leslie matrix model. They suggested that carrying capacity, poaching, survival of 1-year groups, sub-adult female mortality and young male mortality affect the population dynamics. They identified carrying capacity of the patch as the most important factor restricting population increase and showed that inter-birth interval has more serious consequences on populations than other parameters. Our sensitivity analysis indicated that female mortality and percentage of adult females producing one cub are the most important factors influencing the population. Because female mortality, percentage of females producing one cub and inter-birth interval are correlated and have important effects on fecundity of adult females, their results support our model. However, the Qingling and Wolong populations are different. The Qingling population is well conserved in China (Pan et al., 1994; Zhang, 1994). It has a higher growth rate and has been near the carrying capacity since 1979, which often limits population growth. In contrast, the Wolong population still suffers from human activities in the reserve (Liu et al., 2000). It therefore has a very low growth rate and usually does not reach the carrying capacity of the patch (Wei and $\mathrm{Hu}, 1994 \mathrm{a})$.

\subsection{Conservation recommendations}

Our result suggested that promoting the percentage of adult females producing one cub and the carrying capacity of a patch, and reducing individual mortality (especial female mortality) would greatly benefit the giant panda population. Although the current poaching intensity (4.33 individuals/year) does not cause all patch populations of giant panda to become extinct in 100 years, it can cause the average percentage extinction to increase and the total population to decline compared with no poaching. Some small patch populations will go extinct first and, because the pandas cannot disperse among the patches (Fan and Song, 1996; MOF and WWF, 1989), these extinctions actually reduce the distribution and overall population. To avoid small patch populations becoming extinct, there is an urgent need for establishing corridors between suitable patches to facilitate dispersion and colonization of the patches.

The actual effects of poaching on the giant panda are greater than that predicted by our model under the current poaching intensity, which was based on the numbers of skins confiscated representing the minimum number killed. However, poaching is illegal and not all cases are revealed (Li et al., 2000) so we have probably underestimated panda deaths from poaching. Some anecdotal information shows the seriousness of unrevealed cases. For example, there were 153 cases of illegal trade in the giant panda during 1989-1992 ( $\mathrm{Li}$ et al., 2000). Our simulation results showed that even small numbers of individuals removed stochastically from the population may drastically lower population size. Therefore, the giant panda is certainly threatened by poaching, and effective measures should be taken to decrease poaching activity.

The penalty for illegal poaching and trade in the giant panda ranges from imprisonment to death ( $\mathrm{Li}$ et al., 2000). Several illegal poachers and traders have been sentenced to death and hundreds sent to prison but poaching still continues. Better enforcement of existing legislation and conservation education are urgently needed.

Capturing wild pandas for zoos and breeding facilities can play an important role in promoting conservation consciousness of people and conservation education and in raising conservation funds. However, captive panda populations are not self-sustaining. Out of a total of 240 individuals captured between mid 1950s and mid 1990s, only 113 pandas now survive in zoos or breeding facilities (Zheng and Zhao, 1994). They are maintained only by capturing wild pandas and this reduces the total population. Our model under-estimated the effects of this capturing because it did not include the number 
that died during capture or transporting to zoos etc. The percentage of captive animals is about $20 \%$ of the total panda population. Few mammal species in China have such high percentage of captive population in their total populations. For the Asiatic black bear (Ursus thibetanus) the percentage of captive individuals can reach about 33\% (Ma, 1998), but this captive population is selfsustaining and the wild population is very large.

The government has prohibited capturing pandas for zoos since 1990 (Zhou and Pan, 1997). However, its effectiveness is limited because, with the development of ecological tourism in China, many reserves have established wildlife parks or endangered animal breeding facilities for tourists in recent years. Some giant pandas in the local parks or breeding facilities are from the wild (Zheng and Zhao, 1994) and other reserves are planning to establish the local wildlife parks or breeding facilities. This would be a new threat to the wild panda population. There is, therefore, a need for tighter regulations to prohibit capturing wild panda for zoos or breeding facilities.

\section{Acknowledgements}

This research was supported by "973" program (G2000046805), a grant from Chinese Academy of Sciences (KSCX2-SW-118 and C2999083) and a grant from the National Science Foundation (39893360), CAS Innovation Program and the Spatial Ecology Program of the Department of Ecology and Systematics, University of Helsinki, Finland. We thank B.N.K. Davis, C.J. Loucks, and an anonymous reviewer for their valuable comments on the manuscript.

\section{References}

Akcakaya, H.R., Burgman, M.A., Ginzburg, L.R., 1997. Applied Population Ecology. Applied Biomathematics. Setauket, New York.

Boyce, M.S., 1992. Population viability analysis. Annual Review of Ecology and Systematics 23, 481-506.

Brook, B.W., O'Grady, J.J., Chapman, A.P., Burgman, M.A., Akcakaya, R., Frankham, R., 2000. Predictive accuracy of population viability analysis in conservation biology. Nature 404, 385-387.

Burgman, M.A., Lamont, B.B., 1992. A stochastic model for the viability of Banksia cuneata population: environmental, demographic and genetic effects. Journal of Applied Ecology 29, 719-727.

Burgman, M.A., Ferson, S., Akcakaya, H.R., 1993. Risk Assessment in Conservation Biology. Chapman and Hall, London.

Chapman, A.P., Brook, B., Blutton-Brock, T.H., Grenfell, B.T., Frankham, R., 2001. Population viability analyses on a cycling population: a cautionary tale. Biological Conservation 97, 61-69.

Eltringham, S.K., 1984. Wildlife Resources and Economic Development. John Wiley and Sons, Chichester.

Fan, Z., Song, Y., 1998. Habitat corridors for the giant pandas. In: Jiang, Z., Han, X., Ma, K. (Eds.), Conservation Biology. Zhejiang Science and Technology Press, Hangzhou, pp. 206-211. (in Chinese with English abstract).

Gilpin, M.E., Soulé, M.E., 1986. Minimum viable populations, process of extinction. In: Soulé, M.E. (Ed.), Conservation Biology: The
Science of Scarcity and Diversity. Sinauer Associate, Sunderland, MA, pp. 19-34.

Hu, J.C., 1998a. Ailuropoda melanoleuca. In: Wang, S. (Ed.), Chian Red Data Book of Endangered Animals. China Science Press, Beijing, China, pp. $158-165$.

Hu, J.C., 1998b. Returning to the nature and protection of giant pandas. In: Hu, J.C., Wu, Y. (Eds.), Resource and Conservation of Vertebrate. Sichuan Science and Technology Press, Chengdu, China, pp. 3-7. (in Chinese).

Hu, J.C., Schaller, J.B., Pan, W.S., Zhu, J., 1985. Wolong's giant panda. Sichuan Science and Technology Press, Chengdu. (in Chinese).

IUCN, 1994. IUCN Red List Categories. IUCN, Gland, Switzerland.

Kenney, J.S., Smith, J.L.D., Starfeied, A.M., McDougal, C.M., 1995. The long-term effects of tiger poaching on population viability. Conservation Biology 9 (5), 1127-1133.

Krebs, C.J., 1999. Ecological Methodology. Addison Wesley Longman, Inc, England.

Lacy, R.C., 1993. VORTEX - a model for use in population viability analysis. Wildlife Research 20, 45-65.

Lacy, R.C., Hughes, K.A., Miller, P.S., 1995. VORTEX: a stochastic simulation of the extinction process: use's manual. Version 7. Conservation Breeding Specialist Group, World Conservation Union/ Species Survival Commission, Apple Valley, Minnesota.

Lande, R., 1993. Risks of population extinction from demographic and environmental stochasticity and random catastrophes. American Naturalist 142, 911-927.

Leslie, P.H., 1945. The use of matrices in certain population. Mathematics Biometrika 33, 183-212.

Li, Y., Gao, Z., Li, X., Wang, S., Niemelä, J., 2000. The illegal wildlife trade in Himalayan region of China. Biodiversity and Conservation 9, 901-918.

Liu, J., Linderman, M., Ouyang, Z., Li, Y., Zhang, H., 2000. Ecological degradation in protected area: the case of Wolong Nature reserve for giant pandas. Science 292 (5514), 98-101.

Lu, Z., 1992. Population Dynamics, Activity Type and Reproductive Organization of Qinling's Giant Panda Population. PhD Thesis, Peking University (in Chinese).

Ma, S., 1998. Ursus thibetanus. In: Wang, S. (Ed.), Chian Red Data Book of Endangered Animals. China Science Press, Beijing, China, pp. 177-181.

McCarthy, M.A., Lindenmayer, D.B., 1999. Incorporating metapopulation dynamics of greater glider into reserve design in disturbed landscapes. Ecology 80, 651-667.

Mclean, I.F.G., Wright, A.D., Williams, A., 1999. The role of legislation in conserving Europe's threatened species. Conservation Biology 13, 966-969.

McNeely, J.A., Miller, K.R., Reid, W.V., Mittermeier. R.A., Werner, T.B., 1990. Conserving the World's Biological Diversity. IUCN, WWF, World Bank.

Meng, X., 1989. Giant panda conservation. In: Sheng, M. (Ed.), China Forestry Yearbook 1989. China Forestry Press, Beijing, China, pp. 75-76. (in Chinese).

Middleton, D.A.J., Nisbet, R.M., 1997. Population persistence time: estimates, models and mechanism. Ecological Applications 7 (1), $107-117$.

MOF and WWF. 1989. A Comprehensive Survey Report on China's Giant Panda and its Habitat. China Alliance Press, Hong Kong, China.

Pan, W., Lu, Z., Zhu, X., 1994. Population dynamics of Qinling giant pandas: research on number, age and sex structure and internal distribution pattern. In: Zhang, A., He, A. (Eds.), Minutes of the International Symposium on the Protection of the Giant Panda. Sichuang Science and Technology Press, Chengdu, Sichuan, China, pp. 132-138. (in Chinese).

Pielou, B.C., 1971. Mathematical Ecology. Wiley-inscience.

Pimm, S.L., Gilpin, M.E., 1989. Theoretical issues in conservation 
biology. In: Roughgarden, J., May, R.M., Levin, S.A. (Eds.), Perspectives in Ecological Theory. Princeton University Press, Princeton, pp. 287-305.

Possingham, H.P., Lindenmayer, D.B., Norton, T.W., 1993. A framework for improved threatened species management using Population Viability Analysis. Pacific Conservation Biology 1, 39-45.

Rushton, S.P., Barreto, G.W., Cormack, R.M., Macdonald, D.W., Fuller, R., 2000a. Modelling the effects of mink and habitat fragmentation on the water vole. Journal of Applied Ecology 37, 475490.

Rushton, S.P., Lurz, P.W.W., Gurnell, J., Fuller, R., 2000b. Modelling the spatial dynamics of parapoxvirus disease in red and grey squirrels: a possible cause of the decline in the red squirrel in the UK. Journal of Applied Ecology 37, 997-1012.

SAS Inc., 1993. User's Guide. SAS Institute.

Stacey, P.B., Taper, M., 1992. Environmental variation and the persistence of small populations. Ecological Applications 2, 18-29.

van Groenendael, J., de Kroon, H., Caswell, H., 1988. Projection matrices in population biology. Trend in Ecology and Evolution 3, 364-369.

Wei, F., Hu, J., 1994a. Population viability analysis for Wolong panda population. In: Zhang, A., He, A. (Eds.), Minutes of the International Symposium on the Protection of the Giant Panda. Sichuang
Science and Technology Press, Chengdu, Sichuan, China, pp. 116122. (in Chinese).

Wei, F., Hu, J., 1994b. A study of breeding of wild giant pandas in Wolong Natural reserve. Acta Theriologica Sinica 14 (2), 243-248. (in Chinese).

Wei, F., Hu, J., Xu, G., 1989. A study of the life Table of wild giant pandas. Acta Theriologica Sinica 9 (2), 81-86. (in Chinese).

Yang, R., Zhang, F., Lou, W., 1981. A preliminary discussion on the cause of the disastrous death of the giant panda. Acta Theriologica Sinica 1 (2), 127-135. (in Chinese).

Zhang, J., 1994. Giant panda's present condition and protection policy in Foping. In: Zhang, A., He, A. (Eds.), Minutes of the International Symposium on the Protection of the Giant Panda. Sichuang Science and Technology Press, Chengdu, Sichuan, China, pp. 75-78. (in Chinese).

Zheng, S., Zhao, Q., 1994. A breeding plan of captive giant pandas. In: Zhang, A., He, A. (Eds.), Minutes of the International Symposium on the Protection of the Giant Panda. Sichuang Science and Technology Press, Chengdu, Sichuan, China, pp. 22-32. (in Chinese).

Zhou, Z., Pan, W., 1997. Analysis of the viability of a giant panda population. Journal of Applied Ecology 34, 363-374.

Zhu, J., Long, Z., 1983. The vicissitudes of the giant panda. Acta Zoologica Sinica 29 (1), 93-104. (in Chinese). 